\title{
Death, near death, and an antibiotic
}

\author{
Lynne L. Johnson, MD ${ }^{\mathrm{a}}$ \\ a Columbia University, New York, NY
}

Received Aug 17, 2017; accepted Aug 17, 2017

doi: 10.1007/s12350-017-1053-2

\section{See related article, pp. 94-100}

The study by Yamaki et al describes experiments performed in a NZW rabbit model of myocardial ischemia/reperfusion to test their hypothesis that the drug minocycline when administered after onset of the ischemic event limits infarct size by reducing the apoptotic process that leads to necrotic cell death. To demonstrate this therapeutic effect, they compare myocardial uptake of a necrosis avid radiotracer (In-111 labeled GSAO) in the drug-treated rabbits compared to placebo. This manuscript introduces several interesting subjects: the relationship between myocyte apoptosis and necrosis in evolving myocardial infarction, and the pleiotropic cytoprotective properties of a synthetic tetracycline antibiotic patented in 1961.

In animal models of early myocardial infarction and ischemia/reperfusion, as severe hypoxia releases damaging cytokines and free radicals, cells struggling to survive undergo an ordered energy requiring process of cell death called apoptosis. If oxygen is restored, the apoptotic process can reverse and some cells recover but without oxygen cells eventually sustain irreversible damage and die. ${ }^{1,2}$ The quantitative uptake of a radiotracer targeting apoptosis identifies cells that are destined to die plus cells that may recover depending on multiple factors in the local environment and therefore has the potential to over-estimate the extent of ultimate myocardial damage. Annexin A5 is a naturally occurring protein that binds phosphatidylserine, normally retained on the intracellular sarcolemmal membrane, but flipped to the extracellular membrane surface during an early stage in apoptosis. On the outer surface, PS is available

Reprint requests: Lynne L. Johnson, MD, Columbia University, 622 West 168th St, New York, NY 10032; lj2129@cumc.columbia.edu J Nucl Cardiol 2018;25:101-3.

$1071-3581 / \$ 34.00$

Copyright (c) 2017 American Society of Nuclear Cardiology. for binding to a radiolabeled annexin $\mathrm{V}$ protein. Labeled with ${ }^{99 \mathrm{~m}} \mathrm{Tc}$ via the bifunctional chelator HYNIC (hydrazinonicotinamide), ${ }^{99 \mathrm{~m}} \mathrm{Tc}$ HYNIC-Annexin A5 has proven sensitive for detecting apoptosis in myocardial ischemia and infarction in animal models and in pilot studies in patients. ${ }^{3-6}$ Quantitative uptake has correlated well with estimates of ultimate infarct size. ${ }^{7}$ Serial injections and imaging of ${ }^{99 \mathrm{~m}} \mathrm{Tc}$ HYNIC-Annexin A5 can document therapeutic benefits of novel therapies to reduce myocyte apoptosis in acute myocardial infarction. ${ }^{8}$ A novel non-derivitavized annexin $\mathrm{V}$ protein was developed by investigators at Stanford University to directly labeled with ${ }^{99 \mathrm{~m}} \mathrm{Tc}$ at a single specific site at the $\mathrm{N}$ terminus sequence Ala-Gly-Gly-Cys-Gly-His (annexin V-128). ${ }^{9,10}$ This tracer ${ }^{99 \mathrm{~m}} \mathrm{Tc}$ rhAnnexinV-128 is currently in early clinical trials for other applications in several countries (Advanced Accelerator Applications Saint Genis Pouilly, France).

Radiotracers specifically targeting necrosis have been developed including radiolabeled antimyosin antibody, ${ }^{99 \mathrm{~m}} \mathrm{Tc}$-pyrophosphate, and ${ }^{99 \mathrm{~m}} \mathrm{Tc}$-glucarate but each is limited by either a long half-life, or narrow window of positivity after the event. ${ }^{11-14}$ The radiotracer used in this study, ${ }^{111}$ In-GSAO $\left({ }^{111}\right.$ In $4-(N$ - $(S$-glutathionylacetyl) amino)phenylarsonous acid), is a tripeptide with a trivalent arsenic moiety which binds dithiols, molecules normally located intracellularly and absent from extracellular space. A cell membrane transferase upregulated in ischemic stress can transport GSAO metabolite into the cell but modified with a chelator to bind the reporter, the probe cannot cross the cell membrane. When the sarcolemma disrupts during irreversible damage, the tracer binds the dithiols and thereby signals irreversible cell death. In a previous preclinical study, Tahara and co-investigators first describe results of imaging acute myocardial infarction using ${ }^{111}$ In-GSAO. ${ }^{15}$ They studied mice and rabbits. In mice, they showed very nicely by dual fluorescence, staining for annexin A5 on the cell membrane and staining for GSAO intracellularly. ${ }^{15}$ In rabbits with reperfused myocardial infarctions, they compared uptake of ${ }^{111} \mathrm{In}-\mathrm{GSAO}$ with ${ }^{99 \mathrm{~m}} \mathrm{Tc}$-Annexin A5 against 
histological staining for apoptosis using both TUNEL and caspase staining and found a good correlation in uptake between the two tracers and with the quantitative immunohistology.

In comparing annexin A5 and GSAO, the question must be asked: how important is it clinically to exclusively target necrosis and not apoptosis which might include some salvageable cells. If the extent of ischemic damage is the endpoint, then it probably does not matter. Other factors to consider are the several photopeaks and longer half-life of ${ }^{111}$ In limiting dosimetry compared to ${ }^{99 \mathrm{~m}} \mathrm{Tc}$ with shorter half-life and single photopeak. With these minor drawbacks to both tracers, we can conclude that they have equal applicability as non-invasive tools to follow the efficacy of a novel treatment to limit infarct size.

This brings us to the other interesting subject in this manuscript - the novel drug minocycline. Minocycline synthesized in Lederle Laboratories in 1961 came into commercial use in 1971. While current uses as an antibiotic include skin infections, Lyme disease, and MRSA infection, properties unrelated to its antibiotic function are of greatest interest. ${ }^{16}$ These properties include anti-inflammatory and anti-apoptotic properties as well as high lipophilicity allowing it to penetrate into the brain. ${ }^{16}$ Its early reported neuroprotective properties led to applications in neurological disorders. There are currently 232 registered clinical trials of minocline in the US (Clinical Trials.gov). The majority are in neurological and psychiatric disorders but also in asthma, renal disease, multiple sclerosis, rheumatoid arthritis, and ischemic stroke. Expanding from neuroprotection to possible cardioprotection, several preclinical studies administered minocycline in cardioplegia and in ischemia/reperfusion injury models and found beneficial results. ${ }^{17,18}$ Further studies investigated mechanisms and found that minocycline reduces/inhibits several important mediators of inflammation and apoptosis including high mobility group box 1 protein (HMGB1) an early mediator of inflammation and poly(ADP-ribose) polymerase-1 (PARP-1) extensively activated in ischemic tissue where it releases apoptotic-inducing factors. ${ }^{19,20}$

In this current study, the investigators used microSPECT/CT imaging to demonstrate lower uptake of GSAO in risk regions of minocycline-treated rabbits compared to saline-treated control rabbits. They confirmed their in vivo findings with quantitative immunohistology and TUNEL staining on tissue from the risk region and remote myocardium. In comparison to previous preclinical studies of minocycline in myocardial ischemic injury, in the current study investigators administered the drug after the onset of ischemia, making the findings more clinically relevant. It would have been of great interest if the investigators had compared GSAO and annexin A5 in the same animal model. If the inhibitory effect on apoptosis is the primary mechanism involved in its therapeutic effect in ischemia/reperfusion one would predict that both tracers would show similar results. As pointed out by the investigators under "Limitations," to confirm cardioprotective effects of GSAO to salvage myocardium in acute MI, it is necessary to perform additional preclinical studies and follow the animals out to the healing phase of infarction, measure ultimate infarct size and LV function. To prove successful myocardial salvage, the minocycline group must have small infarcts and improved function compared to the placebo-treated animals.

\section{Disclosure}

The author has no conflicts to disclose.

\section{References}

1. Saraste A, Pulkki K, Kallajoki M, Henriksen K, Parvinen M, Voipio-Pulkki LM. Apoptosis in human acute myocardial infarction. Circulation 1997;95:320-3.

2. Krijnen PA, Nijmeijer R, Meijer CJ, Visser CA, Hack CE, Niessen HW. Apoptosis in myocardial ischaemia and infarction. J Clin Pathol 2002;55:801-11.

3. Blankenberg FG, Katsikis PD, Tait JF, Davis RE, Naumovski L, Ohtsuki $\mathrm{K}$, et al. In vivo detection and imaging of phosphatidylserine expression during programmed cell death. Proc Natl Acad Sci USA 1998;95:6349-54.

4. Strauss HW, Narula J, Blankenberg FG. Radioimaging to identify myocardial cell death and probably injury. Lancet 2000;356:1801 .

5. Dumont EA, Hofstra L, van Heerde WL, van den Eijnde S, Doevendans PA, DeMuinck E, et al. Cardiomyocyte death induced by myocardial ischemia and reperfusion: Measurement with recombinant human annexin- $\mathrm{V}$ in a mouse model. Circulation 2000;102:1564-8.

6. Hofstra L, Liem IH, Dumont EA, Boersma HH, van Heerde WL, Doevendans PA, et al. Visualisation of cell death in vivo in patients with acute myocardial infarction. Lancet 2000;356:20912.

7. Tekabe Y, Li Q, Luma J, Weisenberger D, Sedlar M, Harja E, et al. Noninvasive monitoring the biology of atherosclerotic plaque development with radiolabeled annexin $\mathrm{V}$ and matrix metalloproteinase inhibitor in spontaneous atherosclerotic mice. $\mathrm{J}$ Nucl Cardiol. 2010;17:1073-81. doi:10.1007/s12350-010-9276-5.

8. Godier-Furnemont AF, Tekabe Y, Kollaros M, Eng G, Morales A, Vunjak-Novakovic G, et al. Noninvasive imaging of myocyte apoptosis following application of a stem cell-engineered delivery platform to acutely infarcted myocardium. J Nucl Med 2013;54:977-83.

9. Tait JF, Smith C, Blankenberg FG. Structural requirements for in vivo detection of cell death with $99 \mathrm{mTc}$-annexin V. J Nucl Med 2005;46:807-15.

10. Tait JF, Smith C, Levashova Z, Patel B, Blankenberg FG, Vanderheyden JL. Improved detection of cell death in vivo with annexin V radiolabeled by site-specific methods. J Nucl Med 2006;47:1546-53. 
11. Johnson LL, Seldin DW. The role of antimyosin antibodies in acute myocardial infarction. Semin Nucl Med 1989;19:238-46.

12. Antunes ML, Seldin DW, Wall RM, Johnson LL. Measurement of acute Q-wave myocardial infarct size with single photon emission computed tomography imaging of indium-111 antimyosin. Am J Cardiol 1989;63:777-83.

13. Corbett JR, Lewis SE, Wolfe CL, Jansen DE, Lewis M, Rellas JS, et al. Measurement of myocardial infarction size by technetium pyrophosphate single photon tomography. Am J Cardiol 1984;54:1231-6.

14. Mariani G, Villa G, Rossettin PF, Spallarossa P, Bezante GP, Brunelli $C$, et al. Detection of acute myocardial infarction by ${ }^{99 \mathrm{~m}} \mathrm{Tc}$-labeled D-glucaric acid imaging in patients with acute chest pain. J Nucl Med 1999;40:1832-9.

15. Tahara NH, Zandbergen R, de Haas HJ, Petrov A, Pandurangi R, Yamaki T, et al. Noninvasive molecular imaging of cell death in myocardial infarction using 111In-GSAO. Sci Rep 2014;4:6826.

16. Brenes-Salazar JA. Minocycline: A bacteriostatic antibiotic with pleiotropic cardioprotective effects. Can J Physiol Pharmacol 2015;93:863-6.
17. Salameh A, Halling M, Seidel T, Dhein S. Effects of minocycline on parameters of cardiovascular recovery after cardioplegic arrest in a rabbit Langendorff heart model. Clin Exp Pharmacol Physiol 2015;42:1258-65.

18. Romero-Perez D, Fricovsky E, Yamasaki KG, Griffin M, BarrazaHidalgo M, Dillmann W, et al. Cardiac uptake of minocycline and mechanisms for in vivo cardioprotection. JACC 2008;52:1086-94.

19. Hu X, Zhou X, He B, Xu C, Wu L, Cui B, et al. Minocycline protects against myocardial ischemia and reperfusion injury by inhibiting high mobility group box 1 protein in rats. Eur J Pharmacol 2010;638:84-9.

20. Tao R, Kim SH, Honbo N, Karliner JS, Alano CC. Minocycline protects cardiac myocytes against simulated ischemia-reperfusion injury by inhibiting poly(ADP-ribose) polymerase-1. J Cardiovasc Pharmacol 2010;56:659-68. 